In a recent book on the Common Raven, Bernd Heinrich notes that "ravens associate with any animals that kill large game" and that "carnivores are reported to be remarkably tolerant of ravens." Wolves, sled dogs, even wolverines are mentioned as paying little attention to ravens attracted to their kills, though Heinrich points out that the "99.5 percent of the time that the wolf is tolerant hardly matters." He goes on to suggest that a raven risks "danger by approaching meat of any kind," for carnivores, including foxes, may still be in the vicinity. ${ }^{1}$

But hunger, says Heinrich, is not the only reason ravens approach carnivores. Ravens that repeatedly sneaked up behind a fox and a Bald Eagle at carcasses set out for bait by photographers in Ontario, for example, were judged by those observers to be doing so out of "desire to impress one's fellow ravens with one's daring. Perhaps these are males doing their chivalrous bit for the females." Heinrich examined filmstrips of these observations and found that the ravens involved were "strutting and feather posturing, doing the classical raven dominance display of courting males." He concluded that the ravens approaching carnivores are demonstrating their suitability as mates by bringing potential suitors to a carcass "to show her that he (and hence she as well) can feed at it. But carcasses are rare; there is not always opportunity for such a demonstration. So the male shows his mettle on substitutes. The bird who approaches a lone wolf will surely dare to approach a carcass."1 Our raven, which certainly had its feathers raised, may thus have been demonstrating its prowess for a distant, watching mate.

Another possible explanation for our observation may be found in David Henry's masterful book on the Red Fox. ${ }^{2}$ Foxes regularly cache food, then return later to dig it up when needed. A long list of scavengers, including ravens, are known to take food from fox caches. Henry notes that corvids will follow a fox carrying food, sometimes for a considerable distance, watch the fox make a cache, then after the fox has moved off, attempt to uncover it. The digging action which I saw our fox do may have been an effort to uncover a cache so that it could feed. When it lay down, it may have been protecting the cache from the raven.

1. HEINRICH, B. 1989. Ravens in winter. Summit Books, Toronto. 379 pp.

2. HENRY, J.D. 1986. Red Fox, the catlike canine. Smithsonian Institution Press, Washington, D.C. 174 pp.

\title{
RAVEN PREDATION
}

On the afternoon of 11 February 1993, I noticed a flock of Common Ravens fly by my seventh-floor office window. As the ravens were not doing their usual aerobatics in the thermal air currents over the office tower, I took a second look. This is when I noticed a Rock Dove being chased and harassed by the ravens. As they flew by beneath my level it was easy to watch what was happening. One raven pecked at and eventually grabbed and held the head of the pigeon. After being released the pigeon appeared injured. It descended, glided and landed on the north side of the river. All seven ravens landed there as well. As I did not see the Rock Dove fly away or the ravens leave the area, I presumed the Rock Dove was killed.

Carmen Dodge, Box 285, Prince Albert, Saskatchewan. S6V 5R5 